\title{
Fast optical signal processing in high bit rate OTDM systems
}

Poulsen, Henrik Nørskov; Jepsen, Kim Stokholm; Clausen, Anders; Buxens Azcoaga, Alvaro Juan; Stubkjær, Kristian; Hess, R.; Dülk, M.; Melchior, H.

Published in:

Lasers and Electro-Optics Society Annual Meeting, 1998. LEOS '98. IEEE

Link to article, DOI:

10.1109/LEOS.1998.737736

Publication date:

1998

Document Version

Publisher's PDF, also known as Version of record

Link back to DTU Orbit

Citation (APA):

Poulsen, H. N., Jepsen, K. S., Clausen, A., Buxens Azcoaga, A. J., Stubkjær, K., Hess, R., Dülk, M., \& Melchior, $\mathrm{H}$. (1998). Fast optical signal processing in high bit rate OTDM systems. In Lasers and Electro-Optics Society Annual Meeting, 1998. LEOS '98. IEEE (Vol. 1, pp. 67-68). IEEE. https://doi.org/10.1109/LEOS.1998.737736

\section{General rights}

Copyright and moral rights for the publications made accessible in the public portal are retained by the authors and/or other copyright owners and it is a condition of accessing publications that users recognise and abide by the legal requirements associated with these rights.

- Users may download and print one copy of any publication from the public portal for the purpose of private study or research.

- You may not further distribute the material or use it for any profit-making activity or commercial gain

- You may freely distribute the URL identifying the publication in the public portal 
The demand for information bandwidth in the telecommunication networks is increasing at a rate making all-optical solutions necessary. To maximise the utilisation of the available transmission bandwidth of the optical fibers two complementary solutions are available, wavelength division multiplexing (WDM), which has reached a very mature state, and optical time division multiplexing (OTDM), which is rapidly maturing. In both cases basic signal processing is done in the optical domain. The WDM technique has many advantages in meshed networks due to the possibility for passive and, hence, relatively simple multiplexing, demultiplexing and routing. In contrast, OTDM requires active signal processing for demultiplexing and individual channel routing. It does, however, also offer several advantages such as simpler dispersion management, simultaneous regeneration of all channels, reduced impact from the EDFA gain profile and other filtering elements, and less cross-talk due to, e.g., four wave mixing (FWM) and stimulated Raman scattering (SRS). Hence, the OTDM technology has been investigated by a number of research groups for point-to-point transmission [1-6]. Stateof-the-art is presently $640 \mathrm{Gbit} / \mathrm{s}$ transmission over $60 \mathrm{~km}$ with clock recovery and demultiplexing [6].

As all-optical signal processing is maturing, OTDM has also gained interest for simple networking in high capacity backbone networks. As an example of a network scenario, Fig. 1 illustrates an OTDM bus interconnecting another OTDM bus, a single high capacity user represented by an optical termination (OT) and a WDM area.

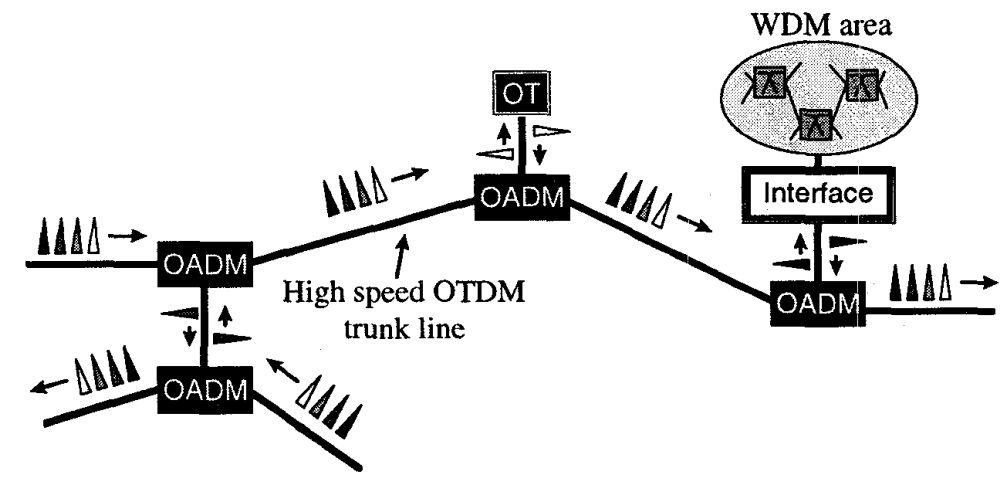

Fig. 1. OTDM bus with add/drop multiplexers for long distance interconnection of, e.g., users with a demand for very high capacity (OT: Optical Termination), large local area networks or another OTDM bus.

In such a network, a number of different optical signal processing functions must be available. At the network nodes, add-and-drop multiplexers (OADM) are needed for dropping channels from the incoming OTDM stream and for adding new channels into the vacant time slots. This operation requires a clock extraction circuit for correct channel selection. The add-channel must be aligned to the vacant time slot and, hence, a synchronisation and buffering functionality is also required. For interfacing to a WDM area, functionalities such as wavelength and format conversion must be present. Finally, some signals may be distorted due to transmission, requiring all-optical regenerators in some of the network nodes.

The requirements to signal processing quality are demanding and will be discussed in detail. For example when dropping a channel, the residual signal in the empty time slot must be suppressed by more than $20 \mathrm{~dB}$ and the channel inserted into the empty time slot must have a 
pulse tail, which is suppressed by more than $30 \mathrm{~dB}$ in the neighbouring time slot. So, high signal quality is a necessity for OTDM networking.

Many of the required high speed functions have been demonstrated using 1) electroabsorption modulators, 2) FWM in semiconductor optical amplifiers (SOA), 3) nonlinear loop mirrors (NOLM) and 4) monolithically integrated Michelson or Mach-Zehnder structures with SOAs incorporated as phase shifting elements. The latter have been demonstrated as compact and highly stable devices that have been used for demultiplexing [7], regeneration [8], add-anddrop multiplexing [9], and format and wavelength conversion [10]. As an example, add-and-drop multiplexing at $40 \mathrm{Gbit} / \mathrm{s}$ in a Mach-Zehnder structure is shown in Fig. 2, with a very efficient clearing of the time slot to add into.

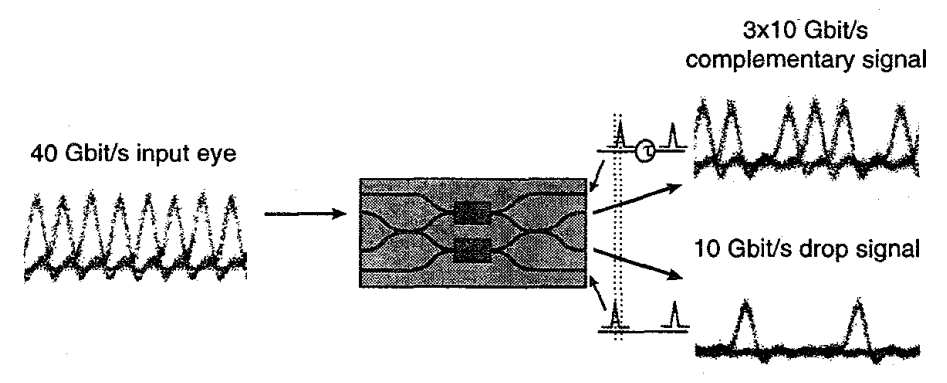

Fig. 2. Add-and-drop functionality in a SOA based Mach-Zehnder interferometer.

The electronics is approaching $40 \mathrm{Gbit} / \mathrm{s}$ line rates pushing OTDM applications towards higher bit rates. However, the all-ready existing OTDM technology is scaleable and will offer $\mathrm{N} \times 40 \mathrm{Gbit} / \mathrm{s}$. The maturing of OTDM is also seen from the number of increasing all-optical functionalities that are demonstrated at bit rates as high as $640 \mathrm{Gbit} / \mathrm{s}$. Hence, the choice of OTDM is a feasible alternative to WDM for some applications. An example could be the upgrade a transmission system, where OTDM would be preferable due to the initial system design. However, OTDM could also be attractive for applications in areas where a serial bit stream is preferred. This could be in, e. g., slotted OTDM where a number of consecutive time slots are allocated a user thereby providing flexible bandwidth on demand at very high burst rates. The combination of OTDM and WDM is interesting, since the line bit rate in each WDM channel can be increased thereby lowering the number of necessary WDM channels.

\section{References:}

[1] R. A. Barry et al., J. Select. Areas in Comm., 14, 999 (1996).

[2] S.-W. Seo et al., J. Select. Areas in Comm., 14, 1039 (1996).

[3] A. D. Ellis et al., J. Lightw. Technol., 13, 761 (1995).

[4] S. Kawanishi, in Techn. Dig. OECC'97, paper 8A1-3.

[5] M. Eiselt et al., J. Lightw. Technol., 13, 2099 (1995).

[6] M. Nakazawa et al., in Proc. OFC'98 (San Jose 1998), paper PD-14.

[7] R. Hess et al., in Techn. Dig. OA'97 (Victoria 1997), paper WA3.

[8] A. T. Clausen, in Techn. Dig. OECC'98, (Chiba 1998), Paper 13A1-3.

[9] K. Jepsen et al., in Proc OFC'98 (San Jose 1998), paper ThN2.

[10] K. Jepsen et al., in Proc. ECOC'97 (Glasgow 1996), paper Th3C8. 